\title{
LOS CRITERIOS BINARISTAS EN LA TEORIA LITERARIA. NOTAS EN TORNO A SUS POSICIONES Y FUNDAMENTOS.
}

\section{Lic. Enrique Margery Peña}

\section{ALCANCES PRELIMINARES}

0 . El tema que en esta oportunidad constituye el objeto de nuestras reflexiones ostenta determinadas particularidades que lo hacen en gran parte diferir del común de estudios y artículos que, cualesquiera que sea su extensión y profundidad, aparecen de continuo en publicaciones referidas a la teoría y a la crítica literarias.

En el marco de este ámbito y como problemática general, el binarismo escapa a la especificidad de una metodología definida. No obstante, su insoslayable naturaleza metacritica, así como los rasgos del común de los elementos axiomáticos que lo configuran, determinan la necesidad de fijarlo, aunque apriorísticamente, en torno a la idea de un fundamento criteriológico adoptado, la mayoría de las veces de una manera explícita, por algunas de las más relevantes tendencias críticas que en la actualidad centran su objetivo en la descripción o interpretación de la obra literaria.

0.1 Cabe en primera instancia establecer que bajo la denominación de 'binaristas' entendemos a las concepciones que fundamentan y reducen tal descripción o interpretación a un conjunto siempre jerarquizado de oposiciones privativas que, insertas en uno o más niveles del texto, constituyen su esquema estético expresivo.

0.2 Es indudable que la base de tal concepción en el ámbito de la teoría y crítica literarias, al igual que en la antropología, la psicomecánica y la propia cibernética, ha tenido su fuente de origen en los métodos de la fonología estructural, que a partir de los postulados de Trubetzkoy y de la axiomática establecida por Jakobson, subordina la distinción o construcción de un sistema o modelo al reconocimiento de la red de oposiciones que configura su textura. Este encuadre, que preside los fundamentos del binarismo, da razón a 10 aseverado por el propio Lévi-Strauss (I, 31) en el sentido de que "la fonología no puede dejar de cumplir, respecto a las ciencias sociales, el mismo papel que la física nuclear, por ejemplo, ha descmpeñado en el conjunto de las ciencias exactas".

Reconociendo la propiedad de la afirmación que el ilustre antropólogo hiciera en 1945, hoy, a más de treinta años, es menester reconocer que en la actualidad los fundamentos binaristas representan una de las proyecciones que la informática ha planteado en el terreno de la teoría de la información.

En su base fonológica, el binarismo se asocia a la noción de oposición privativa, que según la clasificación de las oposiciones de acuerdo con la naturaleza de la relación que hay entre sus términos, se da en Trubetzkoy cuando uno de los términos es caracterizado por la ausencia de una cualidad que el otro tiene (v.gr., sordo/sonoro; denso/difuso; estridente mete, etc.). La operación que implica el reconocimiento de dicha relación es en todo caso equivalente a la elección de unidades equiprobables de códigos también binarios a que recurren la codificación y decodificación cibernéticas, de tan amplia difusión en los últimos años.

0.3 En el curso de estas consideraciones iniciales se hace necesario señalar que el binarismo no ha contado con una aceptación unánime tanto en torno a su validez como a su universalidad. Martinet (Cfr.I, 73 74) estima que para afirmar 
que todas las oposiciones son binarias habría que probar tal hecho, o bien llegar a probar que el hombre, siendo lo que es, no puede más que organizar sus unidades distintivas según tal modelo. Despojada del aparato físico-matemático del que se la ha revestido para hacerla más atractiva a los espíritus ávidos de rigor abstracto -concluye el lingüista francés-, esta teoría más como un objetivo espiritual que como un esfuerzo por coordinar los resultados de observaciones previas. Por otra parte Lévi-Strauss insiste en su idea de que el binarismo representa una excesiva simplificación en las ciencias sociales, aceptable como criterio a lo sumo en una etapa de demostración (Cfr.I, 47 y ss).

0.4 Ya en el plano de la teoría y crítica literarias se hace necesario apuntar a dos hechos que a nuestro parecer han operado decisivamente en su desarrollo.

0.4.1 En primer lugar el desplazamiento del concepto de oposición privativa desde el ámbito fonológico al de las unidades significativas que en el plano de la lexicografía inciara Jean Dubois (Distribution, ensemble et marque dans le lexique - cit. Martinet, II, 285-286) y que en la actualidad se ofrece como la base del estructuralismo semántico y semiológico.

0.4.2 En segundo lugar la proyección crítica de la dialéctica hegeliana que, sobre la base de las nociones de "contradicción", 'síntesis de los opuestos' y 'determinación recíproca', configuraron de suyo una base descriptiva que ya en el idealismo romántico produjo esbozos explicativos de los que bien podría denominarse el 'ethos coetáneo' de algunas formas literarias de la época. Es en esta perspectiva en la que cabría ubicar la oposición 'angelismo/demonismo' de Manzoni; la de 'progreso y civilización' de Scott y aún la de 'civilización y barbarie' de Domingo F. Sarmiento. En el hecho la fijación de oposiciones de acuerdo a la dialéctica no respondía a otra motivación que al intento de entroncar el contenido de las obras de una época al panorama sociocultural que le servía de marco y fundamento.

0.5 Al margen del problema de su debatido valor -ajeno a este trabajo dado que éste se refiere a posiciones que implícita o explícitamente aceptan su validez-, y de las potenciales controversias ligadas a sus orígenes, el binarismo en la teoría y crítica literarias contemporáneas se impone -en un encuadre muy general-como el reconocimiento en la entidad estética de un sistema configurado en torno a una matriz binaria de dicotomías y tensiones que, a la par de una disposición jerarqui. zada, emerge como una síntesis dialéctica que cohesiona la unicidad del discurso literario.

En el común de las posiciones observadas, tal matriz es reconocida en el ámbito de la significa. ción, hecho que obviamente encuentra su origen en la manifiesta referencialidad que comporta el estrato semántico.

Más allá de esta convergencia, las distintas posiciones tienden a agruparse y a distanciarse tanto en sus metodologías específicas como en el grado de su proyección hacia el resto de los estratos de la obra.

0.6 En las siguientes notas intentaremos realizar una rápida revisión de los principales criterios enmarcados en esta fundamentación. A continuación de ello, procuraremos fijar la relevan. cia que en el encuadre binarista ostentan dos nociones: la de 'estructura de la obra literaria' y la de 'cosmovisión'.

Es evidente que estos dos elementos emergen ligados a respectivas problemáticas de contornos muy amplios y complejos. De ellos, no obstante, hemos creído pertinente y lícito considerar sólo aquellos rasgos útiles al conjunto de nuestras reflexiones. Estas, finalmente, deben ser entendidas como un aporte muy general, $\mathrm{y}$ a todas luces modesto, a la clarificación de un problema que ya reclama con urgencia un encuadro definitorio.

1. Reseña de las principales posiciones binaristas en la teoria y critica literarias.

1.0 En un marco histórico el binarismo podría ser visualizado desde los orígenes más remotos del estudio de la literatura. Básicamente el común de las categorizaciones dualistas impuestas por las poéticas y por la crítica en general podrían ser asociadas a tal criterio, desconociendo las substanciales diferencias que separan al dualismo del binarismo. En tal caso estaría aquel inmenso 
caudal de distinciones duales que va desde la Poética de Aristóteles hasta los esquemas nacidos la luz del idealismo romántico que ya citáremos pasando por el operativo tópico del 'menosprecio de corte y alabanza de aldea elaborado por el Renacimiento, hasta la consabida y superada distinción entre 'forma y fondo'. Tales encuadres, cuyos fundamentos valdría la pena algún día agrupar, escapan, sin embargo, al binarismo en su fundamentación actual.

\subsection{El concepto de 'ley de estructura' o de 'especialidades'}

Fundamentada en un criterio básicamente binario y en el marco de una relativa conceptualización, se ubica la denominada 'ley estructural', instrumento analítico que fuera profusamente esgrimido por un sector bastante amplio de la crítica chilena durante la pasada década. Parece indudable que el empleo de este concepto -debido a las posiciones de Cedomil Goié- se deriva directamente de la teoría kayseriana. Es así como el propio Wolfgang Kayser, al intentar una clarificación de la novela de acuerdo al estrato más significativo comportado por su estructura, señala en referencia a la que distingue como 'novela de espacio' (I, 25-26): "Nosotros llamamos novela de espacio a las novelas en las cuales no una determinada acción sino la diversidad y plenitud de espacios constituye el estrato portador de la estructura". Luego de caracterizar algo someramente tanto al Wilhelm Meister como a Munchnausen como obras de esta especie y de reconocer en ellas la existencia de estas leyes estructurales, concluye el crítico germano (Id, 26): “... La estructura de la novela vacila cuando formas tales como "acción" o "historia" o "ley de estructura de espacios" son consideradas como convenciona. lismos no valederos".

\subsubsection{En su Historia de la Literatura Hispa-} noamericana, obra que definitivamente nos atrevemos a ubicar entre los criterios de New Criticism y del estructuralismo, Goié maneja dicha expresión relacionándola de igual modo con los rasgos de la novela espacial, aún cuando alterna su denominación con los términos 'principio de contraste', 'tensión estructural' 'ley de espacialidades' o simplemente 'antítesis'. De este modo leemos en dicha obra expresiones como las siguientes: "Echeverría fue el primero en poner de manifiesto los contrarios concretos que estaban en juego en la política nacional y en convertirlos con toda la carga de su sentido político, en ley de estructura de espacio en una narración (Id., 54). En relación a los rasgos del movimiento romántico en Hispanoamérica, señala poco más adelante: “... Esta politización de la interpretación de la realidad alcanza su elaboración teórica más elevada en esta generación cuando Sarmiento enuncia su antítesis de civilización y barbarie (...) Esta antítesis convertida en ley de estructura del mundo narrativo permitirá observar con mayor nitidez la universal aceptación de esta forma de legalidad en toda la novela del período y sorprender aún en la novela de costumbres" (Id., 56). Por otra parte en su análisis de Manuela, indica a su vez: “... más allá de la opción política partidista la ley de estructura de espacio presentado puede reconocerse entregada como constante que se despliega a lo largo de toda la obra como la antítesis que configura la construcción misma del mundo en su imagen de totalidad y en sus numerosos momentos parciales" (Id., 60). Posteriormente, y en referencia a los rasgos que ordenan la forma interior de la novelística de la generación de 1852 , se señala: “... Es una ley de espacialidades que ordena el mundo en una contraposición dialéctica que caracterizó Sir Walter Scott como esencialmente romántica y que el saintsimonismo y el positivismo hicieron suya $\mathrm{y}$ con ellos toda tendencia progresista hasta nuestros días. Tratábase de la contraposición de un viejo estado de cosas en descomposición y de la aparición vehemente de un nuevo régimen que sin desplazar todavía las formas impuestas delata sus vicios y propone la reorganización social (...) Esta ley de estructura del mundo narrativo, de sentido político e ideológico, preside universalmente la representación del espacio en la novela y viene a satisfacer perfectamente las necesidades funcionales de la ideología, en cuyo contexto se originaba" (Id., 77). Tomando a Amalia como novela representativa de esta generación, anota el crítico chileno: “... el principio de contraste proclamado por Scott y luego por Mazoni anima la forma interior de la novela y prolonga su intención configuradora sobre todos y cada uno de los aspectos dela novela..." (Id., 80). Finalmente Goié concluye que: “... Esta oposición dialéctica está identificada con la forma interior de la novela hispanoamericana moderna (...) Mediante 
ella se fija el punto de vista teórico y político de la visión de la realidad y se intenta comprender el dinamismo interior de la antítesis..." (Id., 81).

1.2.2 Las extensas aunque necesarias citas dejan en claro que tanto Kayser como Goió hace uso de un concepto de denotación precisa, perc carente de una fundamentación explícita en el interior de sus respectivos sistemas. Sobre la base del empleo más extensivo y caracterizado del término que encontramos en la obra del crítico chileno, se hace posible la extracción de cinco hipotéticas propiedades de esta ley estructural que encuentran su clara explicitación en los textos citados. Estas propiedades serían: a) - Expresa una antítesis dialéctica. b) - Se indentifica operativamente con la forma interior de la novela. c)- Es configurante del mundo narrativo tanto en su totalidad como en cada uno de sus momentos parciales. d) - Es poseedora de una dinámica interior y e)-- Expresa el punto de vista teórico y político de la cosmovisión de la realidad de una época.

1.2.3 Fue precisamente el reconocimiento de esta suerte de 'ley estructural' y con ello de la tensión dialéctica del espacio narrativo, la base analítica que hace ya algunos años utilizáramos en un acercamiento estructural a la novela Ultimas tardes con Teresa, de Juan Marsé. En el planteamiento introductorio de tal enfoque anotábamos entonces (I, 504):

"Cuando se inicia la búsqueda y la determinación de la dicotomía estructurante del mundo narrativo se opera con el criterio de que la novela constituye en sí una cosmovisión personal que reproduce y sintetiza las estructuras que corresponden a la interdependencia entre el escritor y la sociedad de la cual éste emerge (...) Creemos que esta visión general de la realidad, por la naturaleza que la configura, tiende a percibirse como una totalidad dialécticamente polarizada, constitución que el creador aprehende y refleja necesariamente en el producto de su quehacer estético...".
Si bien es cierto que el análisis de la obra del excelente novelista catalán respondió -por la evidente naturaleza dicotómica de su configuración espacial- al método propuesto, éste no salvó -ni era el propósito de aquel trabajo- las objeciones que a un nivel metacrítico sé le pueden hacer.

1.2.4 En este sentido se hace evidente que el rasgo más esencial de esta posición lo constituye el hecho de que los teóricos que la sustentan la ligan exclusivamente a la novela de espacio, en el sentido que Kayser determina para esta especie en su clasificación del género (Cfr. II, 480 y ss). La cuestión fundamental aparece referida entonces a la interrogante de si el concepto de 'ley estructural', y con él sus señaladas propiedades, constituye un rasgo inherente de las llamadas "novelas de espacio' y de que por ende no exista en las denominadas por el mismo criterio alemán 'novelas de acontecimiento' y 'novelas de personaje', ni menos en obras de otros géneros. No encontramos al respecto ninguna respuesta ni en los textos de Kayser ni en los de Goié.

\subsection{El esquema binario de W. Hendricks.}

Un criterio binario de naturaleza dicotómica lo hallamos en el campo del estructuralismo norteamericano, ligado a la posición de William Hendricks. Desde su punto de vista teórico se concibe en el texto la presencia concreta de oposiciones inrreductibles cuando hace notar que la estructura superficial de todas las obras narrativas consiste en dos sub estructuras: la sintagmática y la paradigmática. Haciendo presente que la primera se refiere al argumento, indica que la segunda apunta tanto al personaje como al tema. En su forma precisa para Hendricks, esta sub estructura paradigmática "...consists of two elements in opposition, the opposition being specifiable by a metrix of binary features. The two elements constitute in effect, sets of groupings of all the dramatis personae that appear in the narrative (...) That is to say, it is assumed that the characters appearing in a narrative are polariced, and this polarization is the means whereby the thamatic significance of the narrative is signalled or conveyed. Each character set (elements of the paradigmatic structure) can be given a thematic 
lebel, which is the polar opposite of the lebel given the other set. Posible lebels include Life--Death, Nature-Culture, Past--Present, etc. The implications is that thematic statement cannot be directly made by the author, but only through the use of foils". (I, 166-167).

\subsubsection{Aún a pesar del esquematismo que se} refleja en el planteamiento del teórico norteamericano y de la indudable operatividad potencial de su encuadre en el terreno temático, su real validez tropieza, desde nuestra perspectiva, con la percelación estructural que yace implícita en el enunciado de su formulación. En otras palabras, y sobre la base de una concepción isomórfica que ya se ha hecho casi inherente al concepto de estructura, cabe señalar la dificultad de concebir que la citada matriz binaria quede al margen, aún como proyección, del plano sintagmático y en general de la estructura profunda del texto.

\subsection{El binarismo en la semántica estructural.}

1.4.0 Obvio resulta señalar que cualquier alcance detenido en torno a los fundamentos y a los procesos analíticos de la semántica en relación al plano de la obra literaria, rebasaría largamente los nárgenes del presente trabajo. Nos limitaremos por ello a referirnos en forma muy general al conjunto de elementos que juzgamos pertinentes al objeto de nuestro interés, dejando en claro que al llegar a este punto las fronteras entre los planteamientos semánticos y los semiológicos no son siempre claras y específicas.

1.4.1 Partiendo de la que denomina 'estructura lingüistica elemental' y a la que define como la presencia y relación de dos términos (Cfr. I, 19), establece Greimas que el 'eje semántico' o común denominador de ambos términos-- manifiesta la oposición que se presenta bajo la forma de dos polos extremos de ese mismo eje (Cfr. I, 21). Determinada esta dimensión interior, de la que se desprende la articulación de la significación, el lingüista francés determina el nombre de 'sema' para designar la propiedad obviamente metalingüística - que cada lexema guarda con relación al eje semántico de dicha articuiación. Un esquema simple que es posible derivar de la propia Sémantique Structurel, clarifica, aunque referida al plano fonológico dicha relación (Cfr. I, 20 22). $\begin{array}{ll}\text { 'b' } \quad(\mathrm{S}) & \text { 'p' } \\ \text { sonoro }(\mathrm{A})(\text { Eje de sonoridad) } & \text { No sonoro }(B) \\ \text { Propiedad S }\left(\mathrm{S}_{1}\right) & \text { Propiedad No S }\left(\mathrm{S}_{2}\right)\end{array}$

Luego, la articulación sémica puede ser descrita en la fórmula general:

$$
\text { A }\left(S_{1}\right) \quad r \quad \text { B }\left(S_{2}\right)
$$

$S_{1}$ y $S_{2}$ son 'semas' en la concepción de Greimas y en forma muy general corresponden a los llamados 'rasgos distintivos' por Roman Jakobson o 'elementos diferenciales' de Saussure.

Como en el corpus semántico la naturaleza del sema deviene de su inserción sintagmática, Greimas fija en ésta la capacidad de estructurar 'semas contextuales' que con el nombre de 'clasemas' (Cfr. I, 50 -53), constituyen el núcleo sémico o 'semema', que es el concepto realmente operativo en el esquema analítico del teórico francés.

De este modo llega Greimas a la noción de 'isotopía' que definida como “... el has redundante de catcgorías sémicas" (II, 170), permite establecer por su naturaleza iterativa, los distintos códigos poéticos inventariables en el plano semántico (o semiológico) del discurso.

Reconocibles las isotopías, merced a su iteratividad, Greimás concibe su existencia tanto en la sustancia de la expresión (femas) como en la sustancia del contenido (semas), así como en el plano de la forma, tanto de la expresión (fonemas) como del contenido (sememas). Esto último hace que el isomorfismo constituye en Greimas "el problema capital perlada semiótica poética”, entendiendo por tal "aquel que ro conduzca sino a la homologuización término a término y segmento fónico a segmento semántico de los dos planos del discurso poético" (III, 13-14), obviamente el de la expresión y el del contenido.

De este modo y mediante una rigurosa conceptualización de las categorías significativas del universo semántico, intenta Greimas una demostración concreta de esta metodología, tomando como base la tesis doctoral L'Imaginaire de Bernanos, de Tahsin Yücel y que bajo el título de Un échantillon de description, incluye en la última parte de su Sémantique Structurale (pp. 222-254).

El punto de partida usado por el filólogo turco corresponde a lo que Greimas denomina 'una 
metodología extractiva', anotando al respecto (I, 223): "El punto de partida de la extracción reside en la constatación de la redundancia de ciertos lexemas, representativos, a títulos de hipótesis, de la isotopía a describir. "Operando sobre la base de la iteración de estas unidades lingüísticas y considerando este primer inventario como una muestra restringida, la marcha por los lexemas ya inventariados. De este modo, articulada la invariable redundancia lexemática con la variabilidad sememática, se llega a la determinación de una isotopía de naturaleza binaria que opera a modo de hipótesis inicial (V. gr., en Bernanos, Vida/Muerte). Quedando establecida esta oposición procede una segunda extracción que resulta de la articulación de estos lexemas invariables con la suma de los contextos variables en los que ellos se encuentran. Logrando agrupar un número determinado de estas cualificaciones se llega a un inventario más amplio de isotopías que opera a modo de un esquema lexemático actancial de igual constitución dicotómica (V. gr. en Bernanos, Muerte/Vida; Agua/Fuego; Enojo/Alegría) (Cfr. I, 223-224). Greimas anota al respecto (Id. 224): El procedimiento de extracción aparece entonces, en su conjunto, como una serie de operaciones sucesivas de extracción, cada inventario de contextos extraí. dos permite la extracción y puesta en inventario de otros contextos y así hasta agotar el corpus, es decir, hasta el momento de la última extracción".

Es así como la naturaleza dicotómica del nivel semántico se constituye en propiedades positivas (v.gr., 'animado') y negativas (v.gr., 'no animado'). A partir de este nivel y ya en un plano denotativo o connotativo, los sememas se insertarán en el plano positivo del eje sémico $\left(S_{1}\right)$, de acuerdo a la articulación denominada por Greimas 'eufórica', o bien el plano negativo de tal eje $\left(\mathrm{S}_{2}\right)$, de acuerdo a la articulación 'disfórica'.

Lo que se revela a través de la metodología de Greimas es un intento de instituir una tipología de los objetos poéticos merced al reconocimiento de un número determinado de códigos o matrices binarias por la redundancia de categorías en los diferentes niveles del texto.

1.4.2 Como resulta lógico, los postulados de Greimas han encontrado una amplia acogida en un crecido número de estudios referidos a la poética estructural. Entre éstos son a nuestro juicio ilustrativos por la aguda ilustración de los planteamientos los de Sorin Alexandreseu, Le discours étrange. Essais de définition a partir d'un analyse de "La nuit" de Maupassant (S. Alexandrescu, R. Barthes at alt.: Sémiotique narrative et textuella. Paris, Larousse, 1973, págs 55-95) y el de François Rastier (I, 80-106), Systematique des isotopies.

Rastier en especial, a través de un intento de sistematización estilística de las isotopías en un soneto de Mallarmé, llega a una efectiva visualización de los códigos insertos en la composición y a una concreta demostración de la proyección isomórfica de estos códigos en el plano fonológico de la referida composición acudiendo siempre a un reconocimiento de matrices binarias y de asociaciones eufóricas y disfóricas. En el planteamiento de sus directrices analíticas señala Rastier: "Una isotopía puede ser establecida en una secuencia lingüística de una dimensión inferior, igual o superior a la de la frase. Ella puede aparecer en cualquier nivel de un texto; pueden darse ejemplos muy simples en el nivel fonológico: asonancia, aliteración, rima; en el nivel sintáctico: acuerdo o armonía por la redundancia de marcas; en el nivel semántico: equivalencia definicional, triplicación narrativa. De allí la posibilidad de una estilística de las isotopías". (I, 83).

1.4.3 En la coyuntura de la codificación isotópica, es decir de la relación entre la redundancia semémica y los sistemas axiológicos e ideológicos que la sustentan, se impone pertinentemente la observación de Rastier en torno a las dificultades que devienen de la carencia de bases sistematizadas de descripciones sémicas, hecho que a juicio del crítico va en desmedro de la universalidad del método. En el enunciado del capítulo correspondiente a las Isotopías del Contenido se hace notar (I, 85): "El mayor obstáculo en el estudio de este género de esotopías reside en la falta de descripciones científicas de campos semémicos. Los sememas, en efecto, no están clasificados sintácticamente sino por sus bases clasemáticas y o por sus figuras nucleares, o bien en los diccionarios, generales o especializados, ellos están colocados junto a los lexemas que los recubren. La teoría de los campos semémicos no podrá, al parecer, postular un universalismo, sin antes describir estos campos, al mismo tiempo que los sistemas axioló- 
gicos e ideológicos de la sociedad que han producido los textos estudiados".

1.4.4 Al margen de este reconocimiento, la divergencia fundamental que se alza frente a esta posición no cuestiona ni sus fundamentos lingüísticos ni sus complejas formalizaciones. En general, lo que se entra a cuestionar es la arbitrariedad que origina la hipótesis inivial y que iterativamente irrumpe en el proceso extractivo. Umberto Eco -en defensa de su concepción de obra abierta-- es el que al respecto hace presente (I, 84): “... Cuando Greimas elabơra un sistema de significados para explicar las estructuras narrativas de Bernanos, desprende, sin duda algunas, oposiciones que se pueden encontrar en el texto partiendo de cierta hipótesis de lectura, pero nada impide que otro lector se aproxime a este mismo texto de otra manera y descubra en él otra clave de lectura reduciéndola así a otras oposiciones y valores. Como lo veremos (...) el mensaje estético posee las suficientes cualidades de ambiguedad y de apertura que puedan justificar muchas elecciones posibles".

\subsection{El binarismo en la critica semiológica.}

1.5.0 Cualquier alcance ya en un plano general, ya en un plano específico que se haga con respecto a la crítica semiológica (o semiótica - no estableceremos diferencias entre ambos términos), no puede prescindir de aclarar que el conjunto de postulados que sirve de fundamento a la semiología general está lejos de alcanzar en la actualidad un estatus preciso y sobre todo, autónomo.

Manejando un concepto de signo potencialmente válido para cualquier aspecto de la teoría de la información y a la vez de considerar a la cultura como un conjunto de sistemas de signos (para Roland Barthes, por el hecho de existir la sociedad, cada uso se convierte en signo de ese uso), la Semiología ha terminado por instituirse como un intento de teoría general que agrupa y hacia el cual tienden en la actualidad muchas posiciones estructuralistas y aún propiamente estilísticas. De este modo en el amplio espectro terminológico de la crítica semiológica de la literatura es hoy por hoy difícil abstraer lo que de suyo le corresponde a la lingüística estructural (no hay que olvidar que Hjelmslev consideró como semióticas connotativas al conjunto de semióticas cuyo plano de la expresión constituía una semiótica, como es el caso de la obra literaria); a la estilística sintagmática (M. Rifaterre) y a la semántica estructural (el propio Greimas postula indistintamente sus análisis como semánticos y como semiológicos).

Llevadas no obstante a un campo diferenciado de postulados básicos se deben reconocer a nuestro juicio tres hechos concretos que caracterizan a esta concepción. Tales hechos pueden, a grosso modo, enunciarse del siguiente modo: a)-Concebido el texto globalmente como un signo y reconociendo en él la concurrencia de los planos de la expresión y el contenido - en el sentido glosemático - la crítica semiológica orienta el análisis hacia la forma del contenido que es propiamente la significante de los contenidos estéticos; b) El análisis se centra en el modo de producción de este sistema significante, es decir, en la generación del sentido en el texto dado. c)- El reconocimiento, codificado, del material que la cultura aporta a la producción de estos significados, hecho que se revela en el mesmontaje y montaje de las equivalencias en un plano paradigmático. Lógicamente la concepción semiológica referida al discurso literario rebasa largamente en extensión y complejidad a estos tres aspectos, pero estimamos que los aquí anotados sintetizan sus directrices esenciales.

\subsubsection{Las proyecciones de una experiencia.}

Parece ilustrativo para reconocer la conjunción de la posición semiológica con los criterios binaristas, acudir a lo anotado por Claude Bremond (L'Analyse conceptuelle du Coran, Communications, Paris, 7, 1966) en las referencias hechas con motivo de un análisis computacional que sobre las analogías y oposiciones contenidas en la obra islámica realizaron $\mathrm{M}$. Allard, M. Elziere, J.C. Gardin y F. Hours (Analyse conceptuelle du Coran sur cartes perforées, La Haye, Mouton, 1963). En tal reseña, citada por Umberto Eco (I, 84-85), Bremond hace notar que búsqueda de este tipo "...revelando los lazos de atracción y rechazo que existen entre nociones que uno no soñaría en relacionar, hace aparecer constelaciones inesperadas e inherentes a la estructura misma del texto, aunque imperceptibles a la lectura más atenta".

1.5.2 Como una muestra del caudal de 
análisis semiológicos que en la actualidad inunda las revistas y libros referidos a la crítica literaria, hemos escogido el de Cesar Segre quien en forma previa y esclarecedora a su trabajo descriptivo aclara al respecto:

“...el planteamiento semiológico remite, creo que de forma interesante, a la función determinante del autor desde el momento que emite el mensaje literario. Si la obra tiene un contenido semiológico, es porque el autor la ha conformado de forma determinada (...) El autor, en cuanto primer polo del circuito de la comunicación, es artífice y garantizador de la función significativa de la obra. Y aún más, el autor es el trámite entre las costumbres, lingüísticas y estilísticas, las "escrituras", los "códigos", etc., que se han utilizauo, sin duda originalmente, y nuestra interpretación" (1, 97-98).

Más adelante y ya en su estudio Sistema y estructuras en las "Soledades" de A. Machado, termina por establecer:

“... entre los materiales simbólicos y los significados que se les atribuyen, entre los elementos de sugestión y las auténticas y reales interpretaciones, entre todo esto y la realización formal hay una compleja relación semiológica que se intentará sacar a luz..." $(I, 106)$.

El desarrollo del análisis de las Soledades machadianas lo realiza Segre merced a la elección de un grupo de símbolos ligados a un tema, aunque aclarando sobre la marcha (Id., 106, n.4) que pudo haberse partido de sentimientos o movimientos espirituales siguiendo su realización en simbolos y temas distintos. A continuación el análisis se centra en el reconocimiento de un conjunto de elementos referenciales que apuntando a un número restringido de contraposiciones fundamentales (V.gr., Presente/Pasado; Dolor/Gozo) se reiteran en enlaces y superposiciones a través de la creación del poeta español, configurando así el marco de un sistema significativo que el teórico italiano examina en su proceso construc- tivo, en especial -desde su punto de vista - en las correcciones sufridas por los textos.

\subsection{El binarismo en la critica arquetipal.}

1.6.0 Por último esta apresurada reseña de los más relevantes criterios binaristas nos conduce a un ámbito si bien no opuesto, por lo menos alejado de las posturas hasta aquí consideradas. Se trata de la denominada 'crítica arquetipal' cuya formulación más actualizada y a nuestro juicio más exhaustiva se halla, a nuestro juicio, en los planteamientos de Northrop Frye.

1.6.1 Pasando por alto el real valor que como antecedente de la teoría de Frye le corresponde a los aportes de Jung y J.G. Frazer y en forma general a la totalidad de la crítica mitológica, lo básico es señalar que la perspectiva del ensayista canadiense arranca de su concepción de que si bien el contenido de la obra literaria puede estar emparentado con el dominio de la vida, de la realidad, de la experiencia, de la naturaleza, de la imaginación, de la organización social, etc., no es este contenido el que le da origen a la obra en sí. "Las formas señala Frye (I, 22) - se hacen a partir de otros poemas, las novelas a partir de otras novelas. La literatura se hace partiendo de sus elementos internos y no de externos".

Apoyado en esta concepción Frye se refiere a la literatura -al igual que toda estructura verbal afirmativa - como una técnica de la comunicación. "La poesía, tomada integralmente, no es sólo un vasto conjunto de formas configuradas a imitación de la naturaleza sino al mismo tiempo una de las formas de la actividad humana (Id. 124). Consecuentemente, la crítica de Frye se centra en este aspecto social de la creación literaria, que de este modo es considerada como el centro de la conciencia de una comunidad. El símbolo, como imagen característica y recurrente, asume en esta concepción el papel de elemento comunitario comunicable y para él reserva Frye la denominación de 'arquetipo' (Cfr., 124). Percibidos así los arquetipos como formas rítmicas y estructurales - cíclicas y dialécticas-- Frye desprende la idea de que en el centro de estos símbolos universales se encuentra el mito. "En el mito, señala (Id., 167-168), descubriremos separados de todo contexto los principios estructurales de la literatura". O bien 
gicos e ideológicos de la sociedad que han producido los textos estudiados".

1.4.4 Al margen de este reconocimiento, la divergencia fundamental que se alza frente a esta posición no cuestiona ni sus fundamentos lingüísticos ni sus complejas formalizaciones. En general, lo que se entra a cuestionar es la arbitrariedad que origina la hipótesis inivial y que iterativamente irrumpe en el proceso extractivo. Umberto Eco -en defensa de su concepción de obra abierta-- es el que al respecto hace presente (I, 84): “... Cuando Greimas elabora un sistema de significados para explicar las estructuras narrativas de Bernanos, desprende, sin duda algunas, oposiciones que se pueden encontrar en el texto partiendo de cierta hipótesis de lectura, pero nada impide que otro lector se aproxime a este mismo texto de otra manera y descubra en él otra clave de lectura reduciéndola así a otras oposiciones y valores. Como lo veremos (...) el mensaje estético posee las suficientes cualidades de ambiguedad y de apertura que puedan justificar muchas elecciones posibles".

\subsection{El binarismo en la critica semiológica.}

1.5.0 Cualquier alcance ya en un plano general, ya en un plano específico que se haga con respecto a la crítica semiológica (o semiótica - no estableceremos diferencias entre ambos términos), no puede prescindir de aclarar que el conjunto de postulados que sirve de fundamento a la semiología general está lejos de alcanzar en la actualidad un estatus preciso y sobre todo, autónomo.

Manejando un concepto de signo potencialmente válido para cualquier aspecto de la teoría de la información y a la vez de considerar a la cultura como un conjunto de sistemas de signos (para Roland Barthes, por el hecho de existir la sociedad, cada uso se convierte en signo de ese uso), la Semiología ha terminado por instituirse como un intento de teoría general que agrupa y hacia el cual tienden en la actualidad muchas posiciones estructuralistas y aún propiamente estilísticas. De este modo en el amplio espectro terminológico de la crítica semiológica de la literatura es hoy por hoy difícil abstraer lo que de suyo le corresponde a la lingüística estructural (no hay que olvidar que Hjelmslev consideró como semióticas connotativas al conjunto de semióticas cuyo plano de la expresión constituía una semiótica, como es el caso de la obra literaria); a la estilística sintagmática (M. Rifaterre) y a la semántica estructural (el propio Greimas postula indistintamente sus análisis como semánticos y como semiológicos).

Llevadas no obstante a un campo diferenciado de postulados básicos se deben reconocer a nuestro juicio tres hechos concretos que caracterizan a esta concepción. Tales hechos pueden, a grosso modo, enunciarse del siguiente modo: a) - Concebido el texto globalmente como un signo y reconociendo en él la concurrencia de los planos de la expresión y el contenido -en el sentido glosemático - la crítica semiológica orienta el análisis hacia la forma del contenido que es propiamente la significante de los contenidos estéticos; b) El análisis se centra en el modo de producción de este sistema significante, es decir, en la generación del sentido en el texto dado. c)- El reconocimiento, codificado, del material que la cultura aporta a la producción de estos significados, hecho que se revela en el mesmontaje $y$ montaje de las equivalencias en un plano paradigmático. Lógicamente la concepción semiológica referida al discurso literario rebasa largamente en extensión y complejidad a estos tres aspectos, pero estimamos que los aquí anotados sintetizan sus directrices esenciales.

\subsubsection{Las proyecciones de una experiencia.}

Parece ilustrativo para reconocer la conjunción de la posición semiológica con los criterios binaristas, acudir a lo anotado por Claude Bremond (L'Analyse conceptuelle du Coran, Communications, Paris, 7,1966 ) en las referencias hechas con motivo de un análisis computacional que sobre las analogías y oposiciones contenidas en la obra islámica realizaron M. Allard, M. Elziere, J.C. Gardin y F. Hours (Analyse conceptuelle du Coran sur cartes perforées, La Haye, Mouton, 1963). En tal reseña, citada por Umberto Eco (I, 84 85), Bremond hace notar que búsqueda de este tipo “...revelando los lazos de atracción y rechazo que existen entre nociones que uno no soñaría en relacionar, hace aparecer constelaciones inesperadas e inherentes a la estructura misma del texto, aunque imperceptibles a la lectura más atenta".

\subsubsection{Como una muestra del caudal de}


análisis semiológicos que en la actualidad inunda las revistas y libros referidos a la crítica literaria, hemos escogido el de Cesar Segre quien en forma previa y esclarecedora a su trabajo descriptivo aclara al respecto:

“...el planteamiento semiológico remite, creo que de forma interesante, a la función determinante del autor desde el momento que emite el mensaje literario. Si la obra tiene un contenido semiológico, es porque el autor la ha conformado de forma determinada (...) El autor, en cuanto primer polo del circuito de la comunicación, es artífice y garantizador de la función significativa de la obra. Y aún más, el autor es el trámite entre las costumbres, lingüísticas y estilísticas, las "escrituras", los "códigos", etc., que se han utilizauo, sin duda originalmente, y nuestra interpretación" (1, 97-98).

Más adelante y ya en su estudio Sistema y estructuras en las "Soledades" de A. Machado, termina por establecer:

"... entre los materiales simbólicos y los significados que se les atribuyen, entre los elementos de sugestión y las auténticas y reales interpretaciones, entre todo esto y la realización formal hay una compleja relación semiológica que se intentará sacar a luz...” $(I, 106)$.

El desarrollo del análisis de las Soledades machadianas lo realiza Segre merced a la elección de un grupo de símbolos ligados a un tema, aunque aclarando sobre la marcha (Id., 106, n.4) que pudo haberse partido de sentimientos 0 movimientos espirituales siguiendo su realización en símbolos y temas distintos. A continuación el análisis se centra en el reconocimiento de un conjunto de elementos referenciales que apuntando a un número restringido de contraposiciones fundamentales (V.gr., Presente/Pasado; Dolor/Gozo) se reiteran en enlaces y superposiciones a través de la creación del poeta español, configurando así el marco de un sistema significativo que el teórico italiano examina en su proceso construc- tivo, en especial - desde su punto de vista- en las correcciones sufridas por los textos.

\subsection{El binarismo en la critica arquetipal.}

1.6.0 Por último esta apresurada reseña de los más relevantes criterios binaristas nos conduce a un ámbito si bien no opuesto, por lo menos alejado de las posturas hasta aquí consideradas. Se trata de la denominada 'crítica arquetipal' cuya formulación más actualizada y a nuestro juicio más exhaustiva se halla, a nuestro juicio, en los planteamientos de Northrop Frye.

1.6.1 Pasando por alto el real valor que como antecedente de la teoría de Frye le corres. ponde a los aportes de Jung y J.G. Frazer y en forma general a la totalidad de la crítica mitológica, lo básico es señalar que la perspectiva del ensayista canadiense arranca de su concepción de que si bien el contenido de la obra literaria puede estar emparentado con el dominio de la vida, de la realidad, de la experiencia, de la naturaleza, de la imaginación, de la organización social, etc., no es este contenido el que le da origen a la obra en sí. "Las formas señala Frye (I, 22) - se hacen a partir de otros poemas, las novelas a partir de otras novelas. La literatura se hace partiendo de sus elementos internos y no de externos".

Apoyado en esta concepción Frye se refiere a la literatura -al igual que toda estructura verbal afirmativa - como una técnica de la comunicación. "La poesía, tomada integralmente, no es sólo un vasto conjunto de formas configuradas a imitación de la naturaleza sino al mismo tiempo una de las formas de la actividad humana (Id. 124). Consecuentemente, la crítica de Frye se centra en este aspecto social de la creación literaria, que de este modo es considerada como el centro de la conciencia de una comunidad. El símbolo, como imagen característica y recurrente, asume en esta concepción el papel de elemento comunitario comunicable y para él reserva Frye la denominación de 'arquetipo' (Cfr., 124). Percibidos así los arquetipos como formas rítmicas y estructurales - cíclicas y dialécticas - Frye desprende la idea de que en el centro de estos símbolos universales se encuentra el mito. "En el mito, señala (Id., 167-168), descubriremos separados de todo contexto los principios estructurales de la literatura". O bien 
(II, 144-145):... aquellos los mitos representan los principios estructurales de ésta la literatura. Son a la literatura lo que las figuras geométricas a la pintura. La razón es que la mitología, tomada en su conjunto, suministra una especie de diagrama o plano detallado de todo el conjunto de la literatura, una perspectiva, en clave imaginativa, de la situación humana del principio al fin, de arriba a abajo, de todo lo concebible mediante la imaginación".

Desde esta conceptualizaciôn, y partiendo de dos formas de estructuración simbólicas: el mundo apocalíptico y el mundo demoníaco, Frye concibe un amplio sistema de imaginería analógica que en el plano del discurso literario termina por resolverse en una amplia gama de oposiciones temáticas (v. gr., Paraíso/Infierno; Inocencia/Experiencia; Esfuerzo/Reposo; Vida/Muerte, etc.). Tales oposiciones temáticas configuran las formas sucesivas de un movimiento circular y cíclico (Cfr. I, 193 y ss).

Apoyada esta base dicotómica en la recurrencia también oposicional de las categorías de lo real y lo ideal, que son las que definen la realización de los arquetipos en los géneros, el esquema de Frye se extiende reconociendo en cada género la proyección de la imaginería analógica. Así por ejemplo en su estudio del romance (Relato medieval en prosa o verso que narra las aventuras, generalmente extraordinarias de héroes caballerescos), el ensayista canadiense observa que (I, 229): "... los polos opuestos de los ciclos naturales representan la oposición entre el héroe y su adversarin. El enemigo -agrega-- evoca en e! espíritu la oscuridad, el invierno, la confusión, la esterilidad, la agonía y la vejez y la personalidad del héroe se asocia a la primavera, a la aurora, al orden, a la fecundidad, al vigor y a la juventud".

\section{Alcances a las posiciones reseñadas.}

2.0 Interesa dejar previamente en claro que al margen de este restringido y rápido recuento de criterios binaristas, existen determinadas posiciones e intentos críticos que en un momento de su fundamentación o desarrollo proceden de acuerdo a un reconocimiento de dicotomías o de tensiones estructurantes, sin que tal hecho, pueda inducir a su inclusión en el panorama general de los criterios binaristas. Un caso concreto lo constituyen algunos alcances de la crítica sociológica que más adelante habremos de examinar.
2.1 Ya en el plano de las posiciones reseñadas se debe empezar por reconocer el hecho de que el reconocimiento y sistematización del conjunto de oposiciones yacentes en la obra literaria, representa una apertura analítica que cobra distintas orientaciones en la medida en que cada criterio se aproxima al texto precondicionado por concepciones, metodologías y objetivos y obviamente por terminologías también diversas. A la par de estas diferencias opera el hecho de que cada una de las concepciones demarca la materia de su acercamiento en determinados estratos de la totalidad de niveles que el texto contiene. La ejemplificación de estas aseveraciones queda patente si confrontamos dos de los criterios de más sólidos planteamientos: el semántico estructural y el arquetipal de Northrop Frye.

2.2 Sin embargo, si bien es cierto que el conjunto de los criterios reseñados sustenta, implícita o explícitamente, la idea de la existencia en la obra de una matriz dicotómica ubicable en uno o en la totalidad de sus estratos, no es menos evidente que el binarismo o la tensión polarizada no surgen en ninguno de ellos elevados a una calidad de categoría básica y configuradora por ende, tanto del propio modelo estructural, como de la estrategia de su acercamiento crítico o descriptivo.

Desestimado el criterio de la 'ley de estructura' (su ausencia es absoluta en los actuales estudios críticos), es la metodología descriptiva de la semántica estructural la que más parece acercarse a la postulación de esta esencialidad binarista. Sin embargo es forzoso reconocer que la propia concepción metodológica que iniciara Greimas se plantea como fundamental objetivo "el reconocimiento y determinación de una tipología de los objetos poéticos fundada de este modo en vista de las correlaciones de tales o cuales niveles lingüisticos del discurso poético (Cfr., Greimas III, 7-8). Por lo demás, el examen conceptual de la teoría de Greimas y de la de sus más cercanos seguidores (V.gr., Jacques Geninasca, François Rastier, Jean-Claude Coquet, etc.), revela con amplitud que la misma noción de isotopía así como las distinciones binaristas están siempre en función de la verificación del isomorfismo, que es en verdad la viga maestra de dicha concepción.

\subsection{A la par de este hecho cuya relevancia}


no puede ser desestimada, falta a juicio nuestro, en el común de los criterios, una concepción rigurosa en torno a la entidad o categoría en la que reside la unicidad de la obra y que junto a su función generativa de la matriz oposicional instituya $y$ contenga en sí la coherencia de su substancialidad estético expresiva.

2.4 Finalmente, ya llegados a este punto, $y$ sobre la base de la generalidad de las concepciones expuestas, resulta legítimo estimar que un criterio habrá de constituirse propiamente en binarista en la medida en que reconozca a su vez en el binarismo, el principio constructivơ (no desdeñamos la acepción formalista) de la totalidad estética-significativa impuesta por la obra literaria.

Desde nuestro punto de vista una postulación consecuente de tal criterio, esto es, en función del reconocimiento de un conjunto jerarquizado de oposiciones que desde sus distintos niveles configure totalizadoramente la textura de la obra literaria, habrá de requerir un cuerpo de reflexiones y postulados sobre aquellos elementos y categorías que, convergentes a su verificación, clarifiquen no sólo sus fundamentos, sino su propia metodología descriptiva.

En el curso de las líneas siguientes, y siempre enmarcados en un intento aproximativo, nos centraremos en el examen de dos de estos elementos que, conllevando en nuestro parecer determinadas propiedades que los asocian a la base del criterio que nos ocupa, han motivado por ende este aporte, a todas luces parcial, hacia un aspecto de la teoría literaria que desde hace mucho tiempo reclama un examen integral sobre su compleja problemática.

\section{Binarismo y noción de 'estructura de la obra literaria'.}

3.0 Al considerarse a la obra literaria como una estructura se ha dado origen a una problemática que día a día crece en sus múltiples y complejos perfiles. Partiendo de la amplitud polisémica tanto denotativa como connotativa que el término encierra en que consideramos acertada, en una plano general, la visión de Jean Rousset (Forme et significations, cit. en Jean-Marie Auzias, I, 193-194) cuando apunta: "Il n'y de forme saisissable que là où se dessine un acord, ou un rapport, une ligne de force, une figure obsédante, une trame de présences ou d'échos, un réseau de convergences; j'appellerai "structures" ces constantes formelles, ces liaisons qui trahissent un univers mental et que chaque artiste réinvente selon ses besoins". Las aseveraciones de Rousset, reductibles en un sentido muy amplio a las nociones de 'forma', 'relación' y 'construcción', configuran un eje operativo que es posible encontrar en muchas bases teóricas de los estudios literarios de la actualidad. De este modo Jacques Souvage entiende por 'estructura' (cit., Mariano Baquero Goyanes, I. 18), “...el modo en que los elementos o las palabras se disponen $y$ organizan $-\mathrm{a}$ lo que agrega - La estructura implica siempre un proceso de construcción".

Son muchas, por lo demás, la obra que en el plano de la teoría literaria manejan una conceptualización ligada al contexto de las que Raymond Boudon (I, 63 y ss) determina como definiciones intencionales de la noción de estructura, vale decir aquellas que sin constituir una axiomática precisa se fundamentan en las asociaciones y oposiciones que el término evoca. Asociaciones (estructura-totalidad), (estructura--sistema de relaciones), (estructura-totalidad no ceducible a la suma de sus partes), (estructura-esencia), etc y a las oposiciones (estructura-apariencia), (estructura-característica aparentes), (estructura-agregado), (estructura-sistema superficial), etc. (Id., 66-67).

Tal es el caso de Baquero Goyanes en la obra citada; de Julieta Campos (I,60), para quien la estructura es “... la forma (...), la cristalización del paso de la realidad al arte". El propio Martínez Bonati (Cfr., I, xviii), señala expresamente haber tomado la palabra 'estructura' en un sentido próximo al de 'arquitectura esencial', 'forma constitucional', 'construcción fundamental', en las bases de su relevante obra teórica.

3.1 Con el apoyo de estas conceptualizaciones, un concepto general de estructura de la obra literaria puede ser visualizado en torno a la idea de una forma o totalidad orgánica que contiene $y$ enlaza una serie determinada de elementos cuyas funciones e interrelaciones convergen en la instauración de una significación contingente y cuya unidad y coherencia aparecen sometidas a una necesaria exigencia estética. Este enunciado, producto de una síntesis confrontativa que en lo personal nos hemos atrevido a elaborar, responde a 
las condiciones que Marcelo Pagnini ( $I, 125)$ establece para esta noción en el plano literario, a saber, 'coherencia', 'totalidad' y 'autonomia'. También se ofrece como concordante con la concepción de Umberto Eco (Id., 322) quien al examinar este concepto establece: “...Admitimos, por una suerte de consensus gentium, que la "estructura" es a la vez un conjunto, las partes de este conjunto y las relaciones entre estas partes; que la estructura es un sistema en el cual todo es conexo, el todo y el sistema de conexiones".

3.2 No obstante, al margen del complejo abanico de problemática que es posible desprender de tal noción, nos interesan de ésta aquellos perfiles en los que es posíble reconocer un punto de arranque de la criteriología binarista.

3.3 En tal sentido y a nuestro juicio, la idea, aunque implícita, encuentra su apertura en los postulados generales del formalismo. Uno de los integrantes de la 'Opoiaz', Iuri Tinianov, apuntaba en 1924 refiriéndose a la unidad y dinamismo de la obra literaria:

"La unidad de la obra no es una unidad simétrica y cerrada sino una integridad dinámica que tiene su propio desarrollo; sus elementos no están ligados por un signo de igualdad y adición sino por un signo dinámico de correlación e integración. La forma de la obra literaria debe ser sentida como forma dinámica. Este dinamismo se manifiesta en la noción de principio de construcción. No hay equivalencia entre los diferentes componentes de la palabra; la forma dinámica no se manifiesta ni por su reunión ni por su fusión (...) sino por su interacción a expensas de otro" (I, 87-88).

Como es sabido, la teoría formalista no elaboró una noción de estructura de apreciar este dinamismo constructivo que sus integrantes visualizaron.

Esta concepción encuentra en nuestro parecer su formulación más consistente en la teoría general de Jan Mukarovský, fundador y jefe de la escuela estructural en la estética checoslovaca. Superando de hecho la idea de la estructura artística como la mera interrelación entre el todo y sus elementos, el teórico praguense define la estructura como "...un equilibrio inestable de relaciones", señalando en seguida que "...no se puede calificar de estructura sino al conjunto de elementos cuyo equilibrio interior se rompe y se restablece sin cesar, y cuya unidad aparece, por consiguiente, como una red de contradicciones dialécticas" (Cit., en Oldłich B Blì̌ I, 10). Para Mukarovský esta última propiedad emerge del hecho de que "... siendo que las relaciones que mantienen la unidad de la estructura son de orden dialéctico, la estructura se caracteriza por un incesante movimiento y por incesantes transformaciones" (Belio, 1, 10). Es un hecho que dichas contradicciones dialécticas que se establecen en el interior de la estructura arrancan del carácter mismo de las relaciones de los propios elementos y de éstos con respecto al todo. Es al respecto el propio Belio el que con propiedad señala (Id., 1, 10): “... La noción de estructura está fundada sobre la unificación interior del todo por medio de las relaciones recíprocas entre los elementos y aquélla; y las relaciones no solamente positivas - concordancias y armonías-, sino también negativas -oposiciones y contradicciones-".

Es en esta perspectiva donde la idea de estructura referida al texto literario genera la virtualidad operativa que se inserta en los fundamentos de los criterios reseñados. En este sentido merece ser citada la argumentación de Belio cuando hace notar en relación a este problema (Id., 15):

“...la obra de arte no tiene, en general, un sentido único; ella permite, sobre todo cuando se trata de una obra realmente grande, varias interpretaciones, a veces, irreconciliablemente contradictorias. Nos parece que esa es una prueba muy elocuente de la existencia de tensiones (contradicciones) en la estructura literaria, y una refutación no menos elocuente de la teoría de la convergencia (de una convergencia lineal, mecánica, idílica). Si en la estructura artística todos los elementos convergiesen de una manera armónica, sin 
tensiones ni contradicciones, la obra de arte poseería un solo sentido, perfectamente inequívoco y la posibilidad de muchas interpretaciones no existiría".

No ajena a las bases de esta posición emerge el criterio de Eco cuando concibe la estructura literaria $(I, 85)$ como "una matriz estructurada de funciones en oposiciones alternativas".

3.4 De este modo la obra literaria, concebida como totalidad unificada y unificante, se proyecta como un corpus configurado por la covergencia de una serie de elementos y relaciones que concurren portando irreductibles tensiones al punto de su integración que no puede ser otro que el de su propia funcionalidad estética. Ante la imposibilidad de que dicho conjunto de tensiones pueda disponerse en el corpus de un modo arbitrario surge el binarismo asociado a la calidad de un principio legalizador que, a modo de síntesis básica, neutraliza constructiva y significativamente la concurrencia de las tensiones.

3.5 Entendida esta propiedad estructural deviene la necesaria comprensión de tal principio legalizador en una operación analítica también totalizadora. En referencia a este hecho que ya señaláramos (2.4) es lícito plantear que son las posiciones de Greimas y Frye las que acercándose a este fundamento - si bien lo conciben en estratos diferentes de la estructura - plantean un acercamiento con la calidad anotada.

3.6 Queda en pie, sin embargo, la objeción de Umberto Eco al punto de vista de Greimas en orden a la posibilidad de variadas aproximaciones al texto(1.4.4), y, por ende, del descubrimiento, ya en la operación crítica misma, de diversos ejes oposicionales que tal hecho haría posible en una variedad de lectores.

La objeción del crítico italiano es realmente serio. Obviamente la eventualidad de que de lector a lector y de crítico a crítico, varíe la percepción de los diferentes principios binarios o claves de lectura, en relación a la denominación de sus términos, es una realidad que difícilmente puede ser negada. Tal posibilidad tiende a reafirmarse si entramos a considerar el evidente carácter metadis- cursivo en que se resuelven los enunciados oposicionales.

Y todavía más. Si consideramos la perspectiva de esta objeción, el riesgo mayor radicaría en la posibilidad de que los enunciados contingentes a las dicotomías se originen e inserten 'desde' y 'en' el sistema teórico especulativo del propio crítico o lector y no en las significaciones otorgadas por el propio texto.

$\mathrm{La}$ validez de estas objeciones parece ser, por lo menos en la actualidad, bastante relativa. Sería de interés realizar concretamente tal experiencia y determinar hasta qué punto las diferentes claves de lectura $\mathrm{u}$ oposiciones extraidas por lectores $\mathrm{y}$ críticos diversos, pudieran ser reducidas por medio de una decantación semántica a reducidos ejes de significación verificables en la cobertura lexical de la obra.

Por otra parte no hay que perder de vista que îa objeción de Eco se plantea como referida al método de Greimas y no a la constitución binaria de la estructura que es un rasgo que él comparte (3.3) y acepta.

\section{Binarismo y 'cosmovisión'.}

4.0 Más allá de los fundamentos intrínsecos o extrínsecos instituídos por la crítica literaria, al considerarse a la obra como una estructura originada en un quehacer individual, se plantea la problemática referida al valor y a función de esta individualidad en las directrices de la entidad estática configurada por el discurso literario.

No se trata en este sentido de entrar a reiterar las premisas sostenidas por los criterios histórico-biográficos y psicológicos en torno al rol de la individualidad en el análisis literario, sino de reexaminar la naturaleza de la relación que vincula al creador con la totalidad significada que representa el texto. Creemos que es precisamente en esta totalidad donde cabe reconocer lo que Gramsci denominaba "la coherencia lógica e histórica actual de las masas de sentimientos representados artísticamente(...), la postura ante la vida que circula en la obra de arte misma" (Cit., Ariel Bignami I, 76).

De las múltiples y hasta encontradas posturas que en un plano general se refieren a esta relación, nos parecen relevantes las afirmaciones que Mario Vargas Llosa emitía en su polémica con 
el crítico Angel Rama (A. Rama y M. Vargas Ll. I, 52), donde hacía presente:

"...El proceso de la creación novelesca es individualista en el sentido de que quien lo realiza es un individuo a partir de experiencias que han afectado su vida de manera negativa y profunda. Pero claro que estas experiencias no surgen por generación espontánea 0 milagro (...) Proceden de la situación particular de ese individuo en un sitio $y$ en un tiempo determinados $y$ en ellas se refleja qué duda cabe, la historia, la economía, la moral, ideología de la familia, el grupo, la clase, el país y la cultura o civilización a que ese individuo pertenece(...) De esa red de relaciones y tensiones múltiples que es la vida del escritor, de esa compleja dialéctica donde lo personal, lo histórico y lo cultural se cruzan y descruzan, modificándose mutuamente en un verdadero sistema de vasos comunicantes, pero siempre refractando el nivel de una individualidad, surgen los 'demonios' del novelista".

Por este camino comienzan a vislumbrarse los entornos de la controversia categoría de la 'cosmovisión' o 'visión del mundo' referida a la obra literaria. En nuestro propósito, sin llegar a ahondar en los fundamentos que niegan, condicionan o afirman la existencia de dicha categoría (obviamente nos inclinamos por lo último), nos interesa visualizar en ella aquellos elementos que es necesario considerar en una perspectiva binarista. Desde nuestro punto de vista tales elementos son claramente dos: el lenguaje y el concepto de 'totalidad'.

4.1 En relación al lenguaje como mateiial constructivo de la obra literaria, no cabe duda de que cuando Gramsci sostenía que toda lengua contiene los elementos de una concepción del mundo y que por eso el lenguaje de cada uno revelará la mayor o menor complejidad de su concepción del mundo, el malogrado pensador italiano sintetizaba una de las ideas directrices que a partir de von Humboldt desarrollara la gramática comparada y más modernamente la semasiología.
Es precisamente en relación a esta naturaleza y función de la lengua, que anotaba el célebre linguísta italiano (Cit., H. Sohulte-Herbruggen, I, 125):" En la formación y el uso de la lengua entra necesariamente toda la manera subjetiva de aprehender los objetos, pues la palabra no se forma en la percepción, no es una copia del objeto en sí, sino la imagen que éste ha engendrado en el alma".

Llevado así a una concepción filogenética, el lenguaje en von Humbolt adquiere las formas de una categorización que en forma apriorística se le impone al individuo en relación con la realidad, o, como el propio pensador lo señalara (Id., 123) “...la lengua entera está colocada entre el hombre y la naturaleza que actúa interior y exteriormente hacia él".

Partiendo de estas ideas, reductibles en lo general a la estimación del lenguaje como continente de una Weltanschauung, hubo de surgir muchos lingüistas que reafirmaron, siempre dentro del comparativismo, tal posición. Entre ellos, a modo de ejemplo, Sapir (Selected Writings, cit., Id., 123) llega a afirmar que el hombre "está a merced de su lengua, la que ejerce un poder tiránico sobre su orientación en el mundo". Reafirmativa de tales conceptos en el ámbito semasiológico se impone la valoración de esta propiedad del lenguaje que encontramos en Heinz Schulte-Herbruggen $(I, 123)$, quien, heredero de las teorías humboldtianas, hace presente:

"La lengua nativa representa una especie de esfera intermedia colocada entre el individuo que recibe estímulos, y piensa y la naturaleza con sus diversos fenómenos; figura como una fuerza que influye constantemente sobre él, que lo acondiciona para que ciertos fenómenos le lleguen a ser conscientes mientras que otros pasan inadvertidamente ante él; concentra su atención en unos cuantos sectores de la realidad, matizando ricamente éstos y descartando al mismo tiempo otros; lo guía a ordenar y valorar lo que percibe conforme a las normas que en ellas están establecidas".

En el marco de estas consideraciones se impone la pertinencia del pensamiento de Adam 
Schaff quien, yendo más allá de estas concepciones determina en la lengua una función 'creadora de una imagen de la realidad', concepto que indiscutiblemente se inserta en los fundamentos de la cosmovisión contenida en el plano de la performance. En este sentido señala el lingüista polaco (I,159-161):

“...el hombre piensa siempre en una lengua $y$, en este sentido, su pensamiento es siempre lingüístico. Su lenguaje configura un conjunto de signos y significados; eśpues un pensamiento hablado(...). La manera en la cual un hombre piensa depende, ante todo, de una experiencia filogenética transmitida al individuo por la sociedad(...). Desde este punto de vista, von Humboldt tenía razón al decir que el hombre piensa como habla. Modificando ligeramente la fórmula podría decirse que el individuo considera el mundo y lo concibe a través de los 'lentes de la sociedad'(...) Tenemos que comprender que si el lenguaje modifica la forma según la cual el espíritu copia la realidad, es a su vez, en sí, el producto de la copia, vale decir un producto de la actividad social práctica en la más amplia acepción del vocablo. Así, pues, la segunda parte de la tesis de Humboldt - -esto es, que el hombre no sólo piensa como habla, sino que habla como piensa resulta verificada".

4.1.1 El desplazamiento del concepto de visión del mundo' desde la subsistencialidad lingüística al ámbito específicamente literario es posible apreciarlo en una serie de planteamientos que se disponen desde la consideración del carácter eminentemente verbal de la obra hasta los presupuestos implícitos que hacen a Withhead /Science and the Modern World, cit., Pierre Bourdieu, I, 174) señalar que: "...es en la literatura donde se expresa la visión del mundo concreto. -Agregando que ...Es, por tanto, la literatura la que debemos considerar, y sobre todo sus formas más concretas, si queremos descubrir los pensamientos profundos de una generación".
4.1.2 Desde este punto de vista, el ámbito en que en forma más operativa se ha manejado el concepto de 'visión del mundo' es, sin lugar a dudas, el que corresponde a la sociología de la literatura.

En esta perspectiva la 'visión del mundo' parece encuadrarse en dos claros sectores: por una parte en su denotación goldmanniana, vale decir como estructuras de la conciencia colectiva de un grupo que, constituyendo un conjunto coherente de problemas y respuestas, se expresa literariamente en la creación de un universo de seres y cosas y, por otra, como función que, insertando lo individual en una aprehensión totalizadora lo relaciona, pero no lo subordina a una clase social. En la integralidad de un criterio binarista tal distinción carece de relevancia.

4.1.3 Es precisamente la postura crítica de la teoría sociológica, orientada abiertamente hacia el aspecto político de la obra literaria, la que en la actualidad tiende a ilustrar muestras de análisis de perfiles binarios.

4.1.3.1 Entre éstas sobresale por la gobalidad de su desarrollo la amplia visión crítica de Jacques Leenhardt aplicada al análisis de la $L a$ celocia de Robbe Grillet. Confrontado las nociones de 'escritura' (en la acepción de Roland Barthes) y 'producción' (la escritura no tiene significación ninguna a priori sino que las produce) con el punto de vista sociológico, Leenhardt fundamenta el análisis de la citada obra en los términos siguientes (Leenhardt, I 20-21):

“...La escritura próduce significados, es su trampolín. Los manfiesta, los da a conocer, pero las condiciones necesarias para esas producciones existen con anterioridad. Por eso, la comprensión de las obras literarias como producciones impone al investigador la necesidad de insertarlas dentro del marco de esas condiciones necesarias del orden del pensamiento que llamamos cosmovisión (en cursiva sic). A su vez, cada visión del mundo no existe, propiamente hablando, sino como parte integrante de las funciones sociológicas. Y así, comprender una obra es aclarar su 
relación con una cosmovisión y explicarla es mostrar la función de esa visión del mundo en la estructura sociológica global".

Lo que desde nuestro punto de vista subraya la relevancia de tal postura es el hecho de que ya el análisis concreto resuelve decididamente la cosmovisión - en el intrínseco nivel del narrador-- en un eje estructural que en los planos espacial y mítico responde a la forma de un conjunto de jerarquizadas oposiciones.

Es así como después de distinguir lo que él denomina el 'eje principal' (en La celosía, negro vs blanco), el análisis se centra en el conjunto de constelaciones secundarias, escasamente autónomas' que se elaboran alrededor de esta oposición configurando toda una topografía bipolar, (Cfr., Id., 124).

Desde el ángulo binarista que nos preocupa, y por el hecho de tratarse de un análisis desprendido de la cosmovisión, es interesante la cita donde se concluye dicha exposición: De este modo lo indica Leenhardt (Id., 124):

\begin{abstract}
"Muy cerca del eje principal hallamos, claro está, su expresión inmediata: negro vs blanco convertida en tinieblas vs luz, y todo cuanto participa de uno $\mathrm{u}$ otro se hallaba unido a los ejes secundarios. De esta manera, el sistema asociativo debía proporcionarnos, mediante metáforas sucesivas, una cadena apolínea donde figuraban luz, lenguaje, rectilinearidad, razón, equilibrio, humanidad; y una cadena etónica donde estaban la noche, el ruido, la curva, el instinto, la desmesura, la animalidad. Dos cadenas míticas que agrupaban, siguiendo un sistema bipolar, todo el material predicativo de la narración".
\end{abstract}

4.1.3.2 Instituida la visión del mundo en categoría operativa, el análisis, resuelto en criterios dicotómicos, puede referirse tanto a la totalidad de los elementos del discurso a uno o a varios aspectos parciales de aquel. En el segundo caso nos parece ilustrativo citar el estudio que Nicolás Rosa realizara en torno a la naturaleza y funciones del sexo en la narrativa de David Viñas (N. Rosa. I) Orientado por una metodología básicamente binarista en este análisis del novelista argentino ("cuyo universo se proyecta en abuttadas dicotomías) (Rosa 24), Rosa, a partir de claves simbólicas reiteradas en el plano de las significaciones, llega a la elaboración dicotómica de un 'Esquema libidinal básico' sustentado en tres campos (de la oralidad; visibilidad y manualidad) que concluye proyectando en una axiología biporalizada de valores negativos y positivos referidos a la moral burguesa, entendida como 'escritura' contra la que se alza la obra de Viñas.

4.1.4 En sus términos generales la visión del mundo puede articularse en las formas de una criteriología binarista. No obstante tal aseveración está lejos de explicar en qué elementos de la cosmovisión se fundamenta tal posibilidad y más aún si ella alcanza tanto a la visión como a su plasmación estética.

Desde nuestro punto de vista sólo una percepción consecuente de la noción de 'totalidad' en su real convergencia a esta problemática, permite visualizar y proyectar las formas dicotómicas en la visión del mundo.

4.2 La relación entre 'visión del mundo' y 'totalidad' se da ligada a la estimación de esta última como categoría de lo real y los procesos mentales mediante los cuales la individualidad aprehende la integralidad de los elementos de dicho conjunto. Cabe al respecto referir la existencia de determinados sistemas que en el ámbito de la epistemología niegan la posibilidad de que la individualidad logre la aprehensión totalizadora de aquella infinita gama en la que se resuelve la realidad. Sobre la base de aquellos criterios más imposible sería aún que el individuo pudiera percibir la estructura esencial de aquella totalización. De hecho cualquiera de estas concepciones descarta la visión del mundo ligado a lo individual.

Igual imposibilidad ostenta en el terreno de la teoría literaria la criteriología que niega la vinculación de la obra literaria con la realidad (Croce) o la que considera a la primera como un reflejo, aunque intensificado de la segunda (Lukács).

4.2.1 En nuestro parecer la operativa relación entre la totalidad y lo individual aparece 
resulta -en lo que apunta a lo estético- en la posición teórica de Karel Kosík. Señala al respecto el pensador checo (I, 55-56):

“...La totalidad no significa todos los hechos. Totalidad significa: realidad como un todo estructurado y dialécti$\mathrm{co}$, en el cual puede ser comprendido racionalmente cualquier hecho (clases de hechos, conjunto de hechos). Reunir todos los hechos no significa aún conocer la realidad, y todos los hechos (juntos) no constituyen aún la totalidad. Los hechos son conocimiento de la realidad si son comprendidos como hechos de un todo dialéctico, esto es si no son átomos inmutables, indivisibles e inderivables, cuya conjunción constituye la realidad, sino que son concebidos como partes estructurales de un todo(...) Sin la comprensión de que la realidad es totalidad concreta que se convierte en estructura significativa para cada hecho o conjunto de hechos, el conocimiento de la realidad concreta pasa de sor algo místico, o la incognoscible cosa en sí".

De igual modo, ligada a la posibilidad que va de la abstracción a la totalización -aunque no planteada en el marco dialéctico materialista de Kosík--, Herbert Read (I, 15-16) sostiene que el acto estético “...es el tomar posesión de un segmento descubierto de lo real, establecer sus dimensiones y definir su forma(...) La realidad -agrega Read - es, pues, aquello que de este modo articulamos y lo que articulamos sólo puede comunicarse por su forma estética".

En este ángulo del problema, la relación 'realidad-individuo-totalidad' parece radicar no tan sólo en el 'qué' se percibe, sino que fundamentalmente en el 'cómo' se percibe. Ambos, el 'qué' y el 'cómo' implican la presencia perceptiva de una individualidad en un sistema histórico, socioeconómico y estético cuyas significaciones --y con ellas su compleja red estructural de analogías y disyunciones -. son aprehendidas consciente o inconcientemente por el creador y luego plasmadas en la propia red estructural del discurso literario.
4.2.2 Con estas aseveraciones entramos en el centro de lo que Pierre Bourdieu denomina 'campo intelectual' y que constituye, a decir del estructuralista francés, una suerte de campo magnético en el que los agentes o sistemas de agentes que lo forman pueden describirse como fuerzas que, al surgir, se oponen y se agrega, confiriéndole así una estructura específica en un momento dado del tiempo.(Cfr., Bourdieu, I, 172). De este modo aclara Bourdieu lo específico de sus afirmaciones (Id., 172):

“...el intelectual está situado histórica y socialmente en la medida en que forma parte de ese campo intelectual, por referencia al cual su proyecto creador se define y se integra, en la medida, si se quiere, en que es contemporáneo de aquellos con quienes se comunica y a quienes se dirige con su obra, recurriendo implícitamente a todo un código, que tiene en común con ellos temas y problemas a la orden del dia, formas de razonar, formas de percepción, etc".

Para Bourdieu este 'campo intelecual o cultural' supone la existencia permanente de los conflictos manifestados entre las tendencias y las doctrinas ("los grandes problemas del tiempo"), cuyos opuestos tienden así a plasmarse en una espacialidad integradora. Esta última condición supone para Bourdieu (Id., 178--179), “...el consensus en el disensus que forma la unidad objetiva del campo intelectual de una época dada, consensus inconsciente sobre los puntos focales del campo cultural".

Configurado este inconsciente cultural en las formas de un código que sustenta la relación entre el creador, la obra y su época, el crítico francés termina por señalar (Id., 176):

"Si se corre el riesgo de sorprender al inscribir en el inconsciente cultural las actitudes, las aptitudes, los conocimientos, los temas y los problemas, en suma, todo el sistema de categorías de percepción y de pensamiento adquiridas (...) es porque el creador mantiene con su cultura ilustrada, como con su 
cultura inicial, una relación que puede definirse según el término de Nicolai Hartman, como el de 'llevar y ser llevado'.

4.2.3 Por el camino seguido se llega indefectiblemente a apreciar que la visión del mundo, ligada a la individualidad y entendida como aprehensión totálizadora en la significación aportada por Kosik, es una categoría que parece operar resueltamente en el proceso creativo.

Un problema de interesantes perfiles lo constituye la interrogante acerca de la naturaleza y preeminencia de los materiales que concurren a la integración de dicha categoría. En el panorama actual de la teoría literaria son ya varios los puntos de vista que impulsan la idea de que las estructuras profundas del proceso creativo se configuran no a partir de los elementos entregados por la realidad histórica y social de lo inmediato, sino que tienden a generarse en un entorno literario de formas y significaciones que desde su propia presencia constituyen los materiales de la estructura de superficie o producto del quehacer estético (Northrop Frye, Pierre Macherey, Julia Kristeva). En nuestra perspectiva, representando dicha gestión un esfuerzo tendiente a rescatar la visión del mundo para el terreno de la estética, su concepción no conlleva ningún cambio esencial en su aplicabilidad crítica.

Esta radica en el fondo en el reconocimiento de que la creación literaria arranca de una visión totalizada y totalizadora que, inserta en un espacio (mediatisado o no) de fuerzas antagónicas, capta esta esencial bipolaridad y la encauza denotativa, connotativa, metonímica o metafóricamente en los moldes de una estructura que en sí contiene las matrices para reproducir esa red de antagonismo.

Una alusión crítica que tiende a reafirmar estas aseveraciones, aunque esté referida al plano específico de la novela, la encontramos en la interesante exposición sociológica que sobre dicho género realizara Michal Zéraffa $(I, 54)$. Allí leemos:

"...si el héroe novelístico es víctima de un haz de conflictos o de contradicciones, estos se representan ante el novelista, en compensación, como una especie de cuadro. La realidad, en efecto, aparece dispuesta frente a él como un conjunto de fuerzas conflictuales (fuerza negra y fuerza blanca en Faulkner), sobre cuya base puede imaginar una síntesis, que concretará en su obra mediante el recurso de coordinar esas fuerzas y en nombre y con el auxilio de un principio ideológico fundamental. Este cuadro es la visión del mundo ya "terminada" - del escritor, estado inicial (y real) de la obra aún pendiente de redacción".

Es precisamente la percepción de la realidad en el marco de este panorama donde se entrecrulzan y agazapan innumerables fuerzas antagónicas las que, habiendo orientado la síntesis creativa, debe insertarse en la descripción e interpretación del proceso creador. $Y$ en este sentido donde el binarismo, a juicio nuestro, viene a representar la posibilidad de aprehender el hecho literario en sus más integrales y esenciales dimensiones.

5. Llegamos así al término de estas someras notas. No cabría sin embargo, su fin, sin dejar en claro que la descripción e interpretación del texto en el cauce de tal metodología no es "el método", en el sentido excluyente que ya se ha hecho común en los enunciados de la teoría y la crítica literarias. El binarismo parece constituir "uno de los medios" a nuestro entender el más integralpara acercarse a los significados de la obra literaria.

De igual menera es menester dejar en claro que para alcanzar esta aprehensión integral, carecen la metodología binarista de estudios aclaratorios sobre complejos ámbitos del quehacer estético. Falta, a modo de ejemplo, una definición de la función de las matrices dicotómicas tanto en las estructuras reales de los textos como en sus modelos; falta también un cuerpo de descripciones específicas en relación a la genotextualidad (o intertextualidad, en la terminología de Julia Kristeva) que permita la objetiva comprensión de sus procesos.

Pero por sobre estos inconvenientes, creemos que la descripción e interpretación del texto hechas sobre el desmontaje de las tensiones y dicotomías que instituyen su significación, representa en la actualidad un criterio digno de ser 
intentado en la práctica por quienes desde la crítica, la teoría o la investigación abordan la riqueza del quehacer literario.
Enrique Margcry Peña.
San Ramón 1976.

\section{BIBLIOGRAFIA}

AUZIAS, Jean-Maric (I):Clefs pour le structuralismo. Paris, Seghers, $3^{\mathrm{a}}$ ed., 1971.

BAQUERO GOYANES, Marianos(I): Estructuras de la novela actual. Barcelona, Planeta, $3^{\mathrm{a}}$ ed., 1975. 250 págs.

BI:LIC, Oldrich (I): "La obra literaria como estructura". En: (Problemas de Literatura. Revista Latinoamericana de Teoria y Critica Literaria. Valparaíso, Año I, $N^{O} 1$, enero de 1972 , págs. 9-19).

BIGNAMI, Ariel (I): Arte, ideologia y sociedad. Bs. As., Sílaba, 1973. 109 págs.

BOURDIIU, Pierre (I): 'Campo intelectual y proyecto creador". Ln: Jean Pouillon, Marc Barbut er alt.: Problemas del estructuralismo. México, Siglo XXI, $3^{\mathrm{a}}$ ed., 1969 , págs. $135-182$.

CAMPOS, Julieta (I): Función de la novela. México, Joaquín Mortiz, 1973. 157 págs.

ECO, Umberto (I): La estructura absente. Paris, Mercurc de France, 1972. 447 págss.

FRYl, Northrop (I): Anatomie de la critique. Paris, Gallimard, 1969. 454 págs.

(II): I.a estructura inflexible de la obra literaria Madrid, Taurus, 1973. 411 págs.

GOIC, CIDOMIL (I): Historia de la novela Hispanoamericana. Valparaíso, Ediciones Universitarias de la Universidad Católica de Valparaíso, 1972. 304 págs.

GRIIMAS, Algirdas L (I): Sémantique structurales. París, Larousse, 1966. 262 págs.

(II): "Las relaciones entre la lingüística estructural y la Poética". En: André G. Haudricourt, Georges Granai et alt.: Estructuralismo y Lingüistica. Bs. As., Nueva Visión, 1971, págs. 163-177.

(III): "Pour une théorie du discours poétique". トn: A. J. Grcimas, M. Arrivé et alt.: Essais de sémiotique poétique. París, Larousse, 1972, págs. $5-24$.
HI:NDRICKS, William (1): "Methodology of Narrative Structural Analysis". En (Semiotica, Mount, The !laguc, vii, 2, 1973, págs. 163-184).

KAYSI:R, Wolfgang, (I): "Origen y Crisis de la Novela Moderna". En: 1:ladio García C.: Una Traducción y un Ensavo. San José, Universidad de Costa Rica, 1971, págs. 1 44. (Poligrafiado).

(II): Interpretación y Análisis de la Obra I.iteraria. Madrid, Gredos, $4^{\mathrm{a}}$ ed., 1970. 594 págs.

KOSIK, Karel (1): Dialéctica de lo concreto. México, Grijalbo, 1967. 269 págs.

LIINIIARDT, Jacques (I): Lectura politica de la novela. México, Siglo XXI, 1975. 252 págs.

LIVI STRAUSS, Claude (I): antropologia Estructural. Bs. As., Fudeba, 5, a ed., 1973. 371 págs.

MAR(ilRY P., linrique (I): "Ultimas tardes con Teresa" de Juan Marsé. Una aproximación a sus claves". /Cuadernos Hispanoamericanos, Madrid, $\mathrm{N}^{\mathrm{O}} 279$, septiembre de 1973 , págs. $483-513$ ).

MARTINI:T, André (1): Economie des changements phonetiques. Berne, Fditions A. Francke, $3^{\mathrm{a}}$ ed., 1970. 395 págs.

(II): La Iingüistica. Guia Alfabética. Barcelona, Anagrama, $2^{\mathrm{a}}$ ed., 1975.483 págs.

MARTINI:S BONATI, Iélix (I): l.a estructura de la obra literaria. Barcelona, Scix Barral, $2^{\mathrm{a}}$ cd., 1972. 244 págs.

PAGNINI, Marcello (I): Estructura literaria y' método crítico. Madrid, ldiciones Cátedra, 1975. 268 págs.

RAMA, Angel y Mario Vargas Llosa (I): García Márquez y' la problemática de la novela. Bs. As., Corregidor-Marché, 1973. 89 págs.

RASTII:R, Irancois (I): "Systématique des isotopies". Fin A.J. Greimas, M. Arrivé et alt.: Essais de Sémiotique Poétique. París, Larousse, 1972, págs. $80-106$. 
READ, Herbert (I): Imagen e Idea. México, Fondo de Cultura Económica, $2^{\mathrm{a}}$ ed., 1965. (Col. Breviarios, $\mathrm{N}^{\mathrm{O}}$ 127).

ROSA, Nicolás (I): "Sexo y novela: David Viñas". En su: Critica y Significación. Bs. As., Galerna, 1970, págs. 7-99.

SCHAFl, Adam (I): Problemas del lenguaje. Bs. As., Sudamericana, 1965.

SCHULTE-HERBRUGGIN, Heinz (I): El lenguaje y la visión del mundo. Santiago de Chile. Ediciones de la Universidad de Chile, 1963, 170 págs.
SEGRE, Cesare (I): Critica bajo control. Barcelona, Planeta, $2^{\mathrm{a}}$ ed., 1970.210 págs.

SPITZER, Leo (I): Lingüistica e Historia Literaria. Madrid, Gredos, $2^{\mathrm{a}}$ ed., 1968. 306 págs.

TINIANOV, Iuri (I): "La noción de construcción". Fn: Tzvetan Todorov: Teoría de la literatura de los - formalistas rusos. Bs. As., Signos, 1970, págs. $85-88$.

ZERAFFA, Michel (I): Novela y Sociedad. Bs. As. Amorrortu, 1973. 167 págs. 
$-$

$\$$ 